\title{
LA LIBERTAD DE INFORMACIÓN COMO LÍMITE AL DERECHO A LA PROTECCIÓN DE DATOS PERSONALES: LA EXCEPCIÓN PERIODÍSTICA ${ }^{1}$
}

\author{
CRISTINA PAUNER CHULVI \\ Profesora Titular de Derecho Constitucional \\ Universitat Jaume I. Castellón
}

SUMARIO

I. El derecho fundamental a la protección de datos. Su incidencia en la labor periodística.

II. La excepción periodística en la Unión Europea: la libertad de expresión e información como límite a la protección de datos.

III. La heterogénea recepción de la excepción periodística en las legislaciones nacionales.

IV. La libertad de expresión e información en la propuesta de Reglamento General de Protección de Datos.

V. Conclusiones.

\section{EL DERECHO FUNDAMENTAL A LA PROTECCIÓN DE DATOS. SU INCIDENCIA EN LA LABOR PERIODÍSTICA}

El problema de la conciliación entre las libertades de expresión e información y el derecho a la protección de datos de carácter personal es, sin duda, uno de los más complejos de resolver puesto que la privacidad y el libre flujo de información se consagran como derechos fundamentales en permanente tensión. En este sentido, resulta revelador que el nacimiento del derecho a la privacidad se

1 El presente trabajo se enmarca en sendos proyectos de investigación sobre la reforma del sistema europeo de protección de datos financiados por el Ministerio de Economía y Competitividad (DER201234764) y por la Universitat Jaume I (P1-2012-12). 
produzca, precisamente, a raíz de una polémica protagonizada por el juez Samuel Warren con la prensa norteamericana ${ }^{2}$. Es evidente, además, que el vertiginoso desarrollo de las tecnologías de la información y de la comunicación, destacadamente Internet, ha agravado aquella contradicción al permitir la recopilación y transmisión de información con carácter global y prácticamente imperecedero.

Entendemos, sin embargo, que es posible defender una visión conciliadora entre ambos derechos de modo que el ejercicio legítimo de cada uno de ellos redunde en beneficio del otro y potencie, a su vez, su ejercicio. Así, una adecuada protección de los datos personales puede producir efectos beneficiosos en la libertad de expresión e información. Si no se garantiza adecuadamente su intimidad, cabe la posibilidad de que las personas físicas se muestren reacias a expresar sus ideas. De modo análogo, es probable que la identificación y la descripción del perfil de los lectores y usuarios de los servicios de información reduzcan el deseo de las personas físicas de recibir o difundir información ${ }^{3}$.

El derecho a la protección de datos es un derecho relacionado con el concepto de intimidad pero cuyo ámbito excede al mismo pues disfruta de naturaleza autónoma, entronca directamente con la dignidad de la persona y garantiza una mínima calidad de vida ${ }^{4}$. El contenido de este derecho consiste, brevemente, en el poder de controlar el flujo de informaciones que conciernen a cada persona 5 .

Definido en estos términos, el derecho a la protección de datos plantea importantes condiciones y restricciones al ejercicio de las libertades informativas porque estas implican la puesta a disposición del público de noticias e informaciones que pueden afectar a la privacidad de las personas a las que se refieren. Los datos personales son, actualmente, la savia de la información y la recogida, almacenamiento y difusión de esa información son actividades inherentes al ejercicio de las libertades informativas. Por ello, la normativa reguladora en materia de

2 El derecho a la vida privada surge en los Estados Unidos en 1890 a propósito del caso Warren y Brandeis. La vida privada del señor Warren y de su familia era objeto de constantes y abusivas intromisiones por parte de los diarios de la época por lo que Samuel Warren y su socio Luis Brandeis publicaron su artículo clásico sobre la institución de la privacy en el que suministraban diversos ejemplos de atentados a la vida privada especialmente cometidos por la prensa, sostuvieron que era necesario que se reconociera el derecho a la intimidad y propusieron las reglas generales en la materia y los límites del derecho (WARREN, S. y BRANDEIS, L., «The right to privacy», Harvard Law Review, vol. IV, n. ${ }^{\circ}$ 5, 1890).

3 Tal y como especifica el Informe sobre La protection des donnés et les médias. Etude preparée par le Comité d'experts sur la protection des données (CJ-PD) sous l'égide du Comité européen de coopération juridique (CDCJ), Les éditions du Conseil de l'Europe, Estrasburgo, 1991.

4 Así lo ha manifestado en numerosas ocasiones nuestro Tribunal Constitucional para quien tanto la intimidad, en la esfera más privada de la persona, como la privacidad, en su faceta más externa, se vienen considerando requisitos necesarios para tener una mínima calidad de vida. Por todas, véase la STC 7/2014, de 27 de enero, fj 3 y la jurisprudencia allí citada.

5 En dicción del Tribunal Constitucional, «consiste en un poder de disposición y de control sobre los datos personales que faculta a la persona para decidir cuáles de estos datos proporcionará a un tercero, sea el Estado o un particular, o cuáles puede este tercero recabar, y que también permite al individuo saber quién posee esos datos personales y para qué, pudiendo oponerse a esa posesión o no» (STC 292/2000, de 30 de noviembre, fj 7). 
protección de datos tiene un impacto muy significativo en la labor periodística con implicaciones tanto en la organización de las empresas de comunicación y en el método de trabajo de los profesionales de la información (implicaciones ad intra) como en la publicación y difusión de las noticias (implicaciones ad extra).

De esta forma, por un lado, las previsiones sobre protección de datos deben ser observadas por los ficheros de titularidad privada que manejan los medios de comunicación y en los que se almacenan datos personales de ciudadanos bien se trate de ficheros de personal, ficheros creados con el objetivo de recopilar información de lectores, suscriptores, abonados, concursantes, etc. o, en general, ficheros de gestión, todos ellos vinculados a actividades de carácter comercial de la empresa y que se encuentran totalmente sometidos a la normativa común en materia de protección de datos ${ }^{6}$. Por otro lado, el tratamiento de datos personales en las empresas de comunicación puede estar relacionado con la estricta labor editorial y con la elaboración, redacción y difusión pública de noticias e informaciones. Se trata de ficheros y datos que manejan las empresas de prensa, radiodifusión o televisión para desarrollar su labor profesional y en ejercicio de la libertad de expresión e información. La sujeción de estas actividades a la legislación sobre protección de datos presenta una singularidad puesto que, en la búsqueda del equilibrio entre el legítimo ejercicio de la libertad de expresión e información y la igualmente legítima protección de la privacidad y en atención al papel fundamental que las libertades informativas juegan en el sistema democrático ${ }^{7}$, la normativa europea permite que los Estados miembros establezcan excepciones que suspenden la aplicación de sus previsiones a la actividad periodística. Es lo que se conoce con el nombre de excepción periodística.

En las líneas que siguen analizaremos, en primer lugar, el concepto y alcance de la excepción periodística en la Directiva 95/46/CE del Parlamento Europeo y del Consejo, de 24 de octubre de 1995, relativa a la protección de las personas físicas en lo que respecta al tratamiento de datos personales para detenernos, en segundo lugar, en el examen de las leyes sobre protección de datos de los Estados miembros que, en transposición de la Directiva, han incorporado el reconoci-

6 La imposición de sanciones a medios y productoras por incumplimiento de la normativa sobre protección de datos cuenta con numerosos ejemplos en nuestro país. Véase, por todas, la conocida STS de 17 de abril de 2007, caso Zeppelín Televisión, S.A. que confirmó la multa de más de un millón de euros impuesta por la Agencia Española de Protección de Datos (AEPD) a la productora de televisión Zeppelín por no proteger adecuadamente los ficheros con los datos personales de los candidatos a participar en el programa «Gran Hermano». Un exhaustivo análisis del régimen sancionador de la LOPD y su práctica por la AEPD en RALLO LOMBARTE, A., «Estudio sobre la evolución del régimen sancionador en la legislación de protección de datos», Revista de Estudios Políticos, n. ${ }^{\circ}$ 166, 2014, pp. 95-121.

7 En esta línea, el TEDH ha reconocido desde sus primeras sentencias la trascendencia de la libertad de expresión como «uno de los principales fundamentos de una sociedad democrática y una de las condiciones más importantes para su progreso y el desarrollo individual» (STEDH de 7 de diciembre de 1976, caso Handyside vs Reino Unido, apartado 49) y, por ello, verdadera «piedra angular de los principios de la democracia y de los derechos humanos protegidos por el Convenio» (STEDH de 26 de abril de 1979, caso The Sunday Times vs Reino Unido, apartado 66). 
miento de la excepción periodística. Finalmente, profundizaremos en el estudio de la regulación de esta excepción en la Propuesta de Reglamento Europeo de Protección de Datos que está tramitándose actualmente ante las instituciones europeas con el objetivo de sustituir a la mencionada Directiva y que introduce importantes novedades sobre la cuestión.

\section{LA EXCEPCIÓN PERIODÍSTICA EN LA UNIÓN EUROPEA: LA LIBERTAD DE EXPRESIÓN E INFORMACIÓN COMO LÍMITE A LA PROTECCIÓN DE DATOS}

\section{El intento de conciliación entre privacidad e información en la normativa europea sobre protección de datos}

En el ámbito de la protección de datos, Europa ha desarrollado un complejo acervo normativo cuyo objetivo es garantizar los derechos individuales en esta materia ${ }^{8}$. Así, en primer lugar, el artículo 8 del Convenio Europeo de Derechos Humanos de 1950 (CEDH) consagra el derecho a la vida privada y familiar que, conforme a la doctrina del Tribunal Europeo de Derechos Humanos (TEDH), incluye el derecho a la protección de datos personales. El Convenio 108 del Consejo de Europa, de 28 de enero de 1981, para la protección de las personas físicas en relación con el tratamiento automatizado de datos personales vino a profundizar en la protección de los derechos de los individuos respecto al uso de la informática, en especial en lo que a la vida privada se refiere. Pero el paso definitivo en la consolidación del derecho a la protección de datos como derecho fundamental independiente se dio en el año 2000 con su reconocimiento explícito en el artículo 8 de la Carta de los Derechos Fundamentales de la Unión Europea (CDFUE) que adquiere el mismo valor jurídico que los Tratados y, por tanto, efecto vinculante a partir de la entrada en vigor del Tratado de Lisboa en diciembre de 2009. Finalmente, el artículo 16 apartado 1 del Tratado de Funcionamiento de la Unión Europea (TFUE), introducido por el Tratado de Lisboa, establece el principio según el cual toda persona tiene derecho a la protección de los datos de carácter personal que le conciernan.

Pero el texto de referencia en materia de protección de datos en la Unión Europea lo constituye la referida Directiva 95/46/CE. Esta norma crea un marco regulador destinado a establecer un equilibrio entre, por un lado, un alto nivel de pro-

8 Sobre el tema y con carácter general, recomendamos DAvara RodríGuez, M. A., La protección de datos en Europa: principios, derecho y procedimiento, Servicio de Publicaciones de la Universidad Pontificia de Comillas, Madrid, 1998; Arenas Ramiro, M., El derecho fundamental a la protección de datos en Europa, Tirant lo Blanch, Valencia, 2003; Rebollo Delgado, L., Vida privada y protección de datos en la Unión Europea, Dykinson, Madrid, 2008 y Kuner, CH., European Data Protection Law corporate compliance and regulation, Oxford University Press, Oxford, 2007. 
tección de la vida privada de las personas y, por otro, la garantía de la libre circulación de datos personales dentro de la Unión". Por lo que a nuestro tema de análisis se refiere, el Considerando 17 contempla la aplicación restringida de sus previsiones al tratamiento de datos con fines periodísticos en el sector audiovisual según lo dispuesto en el artículo 9 del mismo texto. Asimismo, el Considerando 37 de la Directiva alude a la necesidad de que, para el tratamiento de datos personales con fines periodísticos o de expresión artística o literaria, se prevean excepciones o restricciones de determinadas disposiciones de la Directiva siempre que resulten necesarias para conciliar los derechos fundamentales de la persona con la libertad de expresión. Finalmente, el artículo 9 de la Directiva establece que los Estados miembros deberán aplicar las exenciones y excepciones necesarias para conciliar el derecho a la intimidad con las normas que rigen la libertad de expresión.

Las excepciones que contempla la Directiva son de obligado cumplimiento aunque «solo si son necesarias», es decir, que únicamente se han de conceder en la medida que sean imprescindibles para lograr un equilibrio entre la defensa de la intimidad y la libertad de expresión. Esto implica que son los Estados miembros quienes deciden cuándo es necesario excluir la aplicación de las normas sobre protección de datos. Excepciones que, como vimos, solo cubren el procesamiento de datos para fines periodísticos, incluyendo la publicación electrónica. Cualquier otra forma de tratamiento de datos por periodistas o por medios de comunicación está sujeta al régimen general de la Directiva (en alusión, por ejemplo, al tratamiento de datos de abonados para fines de facturación o para fines de marketing directo).

\section{El tratamiento de datos personales «con fines periodísticos»: algunos aspectos problemáticos}

A pesar de que el artículo 9 de la Directiva se diseñó con el loable propósito de alcanzar un equilibrio obligatorio entre los derechos e intereses de protección de datos y el interés público en la libertad de expresión, la doctrina ha señalado una serie de fallos significativos en su regulación ${ }^{10}$.

En primer lugar, el mencionado precepto ha sido transpuesto en la legislación de los Estados miembros de forma muy diversa ${ }^{11}$. Aunque la Directiva aspiraba a

9 Esta Directiva general sobre protección de datos se complementa con otros instrumentos jurídicos específicos como la Directiva 2002/58/CE sobre privacidad y comunicaciones electrónicas o la Decisión Marco 2008/977/JAI para la protección de los datos personales en el marco de la cooperación policial y judicial en materia penal.

10 Erdos, D., «A Submission of the DP@CSL Study Group on A Comprehensive Approach on Personal Data in the European Union», pp. 12 a 14. Disponible en http://ec.europa.eu/justice/news/consulting_public/0006/contributions/citizens/dp_at_csls_study_group_en.pdf

11 Sobre el papel del legislador nacional en la implementación del régimen europeo en materia de protección de datos, puede verse Dix, A., «Sub-national Data Protection Laws in a EU Framework», en Data 
crear un nivel equivalente de protección de datos en todos los países de la Unión Europea para garantizar el libre flujo de información en el mercado interior, este objetivo solo ha sido alcanzado parcialmente. Sin perjuicio de un detallado análisis más adelante, advertimos que en algunos países no se prevé ninguna excepción formal para el ejercicio de la libertad de expresión e información en los medios frente a los requisitos exigidos por la normativa sobre protección de datos mientras que en otros casos la expresión periodística se beneficia de una casi absoluta exención de aquellas exigencias. La fragmentación de la normativa de protección de datos y la falta de armonización en la aplicación de estas normas causa no pocos problemas a los medios de comunicación, muy especialmente, en el contexto actual con la expansión generalizada de los nuevos medios digitales y su difusión transfronteriza enfrentándolos a situaciones de inseguridad jurídica puesto que lo que no está admitido por la legislación sobre protección de datos de un país en relación con la recogida, almacenamiento y difusión de datos de carácter personal con fines periodísticos puede ser perfectamente legal en otro y a la inversa.

Esta heterogeneidad está además propiciada por la indeterminación y generalidad del tenor de la norma. Así, la Directiva no proporciona ninguna instrucción sobre qué significa exenciones y excepciones «necesarias» para conciliar el derecho a la intimidad con las normas que rigen la libertad de expresión. No podemos olvidar que existen diferencias muy notables entre países a la hora de definir el contenido y alcance de la libertad de expresión y sus límites son particulares en cada Estado miembro a pesar de que todos suscriben unos principios básicos comunes. Baste mencionar en este sentido la diversa significación de delitos como la negación del holocausto, blasfemia, incitación al odio racial o religioso, apoyo a organizaciones terroristas, pornografía, publicación de los detalles de la vida privada o sexual de los famosos, etc. La propia jurisprudencia del TEDH ha aceptado un «margen de apreciación» a los Estados para la aplicación de las previsiones de la Convención y en los límites que ellos deseen imponer. También el Tribunal de Justicia de la Unión Europea (TJUE) en el caso Linqvist incidió en la discrecionalidad que la Directiva y el $\mathrm{CEDH}$ garantizan a las autoridades nacionales de los Estados miembros ${ }^{12}$.

Por ello, la guía más importante para determinar el alcance de la excepción periodística derivaría no tanto de la Directiva como de la jurisprudencia del TEDH y del TJUE ${ }^{13}$. En esta línea, resulta muy revelador el pronunciamiento del

\footnotetext{
Protection anno 2014. How to Restore Trust? Contributions in honour of Peter Hustinx. European Data Protection Supervisor (2004-2014), Hjelke Hijmans y Herke Kranenborg (eds.), Intersentia, 2014, pp. 129-134.

12 «s cierto que los Estados miembros disponen en muchos aspectos de un margen de apreciación para adaptar su Derecho interno a la Directiva 95/46 (...). Incumbe a las autoridades y a los órganos jurisdiccionales nacionales encargados de aplicar la normativa nacional que adapta el Derecho interno a la Directiva 95/46 garantizar el justo equilibrio entre los derechos e intereses en juego, incluidos los derechos fundamentales tutelados por el ordenamiento jurídico comunitario (que incluyen el derecho a la protección de datos y la libertad de expresión)» (STJUE de 6 de noviembre de 2003, caso Linqvist, C-101/01, apartados 84 y 90).

13 KorfF, D., «Data protection Laws in the EU: The difficulties in meeting the challenges posed by global social and technical developments», en Comparative Study on different approaches to new privacy challenges, in
} 
TJUE en el caso Satamedia donde determina que «han de considerarse actividades de tratamiento de datos personales efectuadas "exclusivamente con fines periodísticos" en el sentido de dicha disposición, si tales actividades se ejercen exclusivamente con la finalidad de divulgar al público información, opiniones o ideas» así como los ficheros de datos personales que contienen únicamente y sin alteraciones, material que ya ha sido publicado por los medios ${ }^{14}$.

Junto a la variedad en el reconocimiento de la excepción periodística en las leyes nacionales, se critica, en segundo término, que el artículo 9 solo proporciona una excepción para el tratamiento de datos para fines «exclusivamente» periodísticos o de expresión artística o literaria. Se denuncia que este enfoque es demasiado restrictivo porque reduce los sujetos que se pueden beneficiar de la excepción, esto es, tan solo periodistas, artistas o escritores ${ }^{15}$. En contraste, el artículo $10 \mathrm{CEDH}$ garantiza a toda persona el derecho a la libertad de expresión que comprende la libertad de opinión y la libertad de recibir o de comunicar informaciones o ideas sin que pueda haber injerencia de autoridades públicas y sin consideración de fronteras.

Debe reconocerse que las nuevas tecnologías han permitido la concurrencia de numerosos instrumentos alternativos a los medios «clásicos» de difusión de la información y hoy en día la web está dominada por contenidos generados por los usuarios, reconvertidos en los principales actores de la comunicación del siglo XxI, y por información compartida, vista y recibida por no profesionales. En este contexto, resulta más difícil reconocer qué elementos caracterizan el ejercicio profesional e incluso puede no resultar unívoco definir la misma profesión periodística. Por ello, se ha denunciado que el artículo 9 tal y como está actualmente diseñado es manifiestamente deficiente llegándose a señalar la conveniencia de aplicar una exención general de la Directiva (la conocida como «excepción doméstica») sobre la base de que se trata de una comunicación no comercial y realizada por individuos ${ }^{16}$. Entendemos, sin embargo, que estas actividades de difusión de información personal a través de las redes sociales no deben quedar exentas con carácter general de los principios en materia de protección de datos habida cuenta de los cada vez más invasivos modos en los que la información personal se maneja y difunde públicamente en las redes sociales ${ }^{17}$.

particular in the light of technological developments, European Commission, 20 January 2010, pp. 11 a 13. Disponible en http://ec.europa.eu/justice/policies/privacy/docs/studies/new_privacy_challenges/final_report_working_ paper_2_en.pdf.

14 STJUE de 16 de diciembre de 2008, caso Satamedia, C-73/07, apartado 64.

15 KorfF, D., «Data protection Laws in the EU: The difficulties in meeting the challenges posed by global social and technical developments...», p. 13.

16 Artículo 3 de la Directiva. Según la interpretación del TJUE en el caso Lindqvist, esta excepción resulta inaplicable cuando la difusión no se hace a «un número indeterminado de personas», lo que constituye una condición intrínseca de la publicación de datos en Internet.

17 Sobre esta cuestión, véase Erdos, D., «Confused? Analysing the Scope of Freedom of Speech Protection vis-à-vis European Data Protection», Oxford Legal Research Paper Series, n. ${ }^{\circ}$ 48/2012, 28 July 2012, pp. 30 a 32. Disponible en http://dx.doi.org/10.2139/ssrn.2119187. 
En principio, las actividades que un ciudadano particular realice en la web en ejercicio de su libertad de expresión e información, siempre que satisfagan los criterios de la finalidad periodística de difusión de material informativo al público relativo a un asunto de interés general, son comparables a las acciones que efectúan los medios de comunicación. Esta interpretación queda explícitamente confirmada, como veremos, en la Propuesta de Reglamento Europeo de Protección de Datos.

\section{LA HETEROGÉNEA RECEPCIÓN DE LA EXCEPCIÓN PERIODÍSTICA EN LAS LEGISLACIONES NACIONALES}

\section{Las derogaciones en interés de la libertad de expresión e información}

A pesar de la heterogeneidad de regulaciones nacionales debe recordarse, no obstante, que la Directiva fija límites y especifica las disposiciones cuya aplicación puede suspenderse cuando nos hallemos ante el ejercicio de la actividad periodística. En concreto, el Considerando 37 habla de «(...) las medidas generales sobre la legalidad del tratamiento de datos, las medidas sobre la transferencia de datos a terceros países y las competencias de las autoridades de control» y no permite prever excepciones a las medidas que garanticen la seguridad del tratamiento. Por su parte, el artículo 9 se refiere al establecimiento de exenciones y excepciones a $«(\ldots)$ las disposiciones del presente capitulo, del capitulo IV y del capitulo VI (...)».

Estas previsiones se refieren a las principales obligaciones que debe cumplir el responsable de tratamiento de los datos y que cabe agrupar en cuatro categorías.

Primera, el principio de calidad de los datos que supone que los datos se tratarán de modo leal, para fines concretos y sobre la base del consentimiento de la persona afectada o en virtud de otro fundamento legítimo previsto por la ley (artículos 6 y $7 . a$ de la Directiva).

Segunda, reglas de transparencia que incluyen la obligación de suministrar información al interesado en el momento de recabar sus datos así como cuando los datos se obtienen de terceras personas (artículos 10 y 11 de la Directiva) y derecho de acceso a los datos del interesado cuando lo solicite (artículo 12 de la Directiva).

Tercera, normas sobre categorías especiales de datos en las que se incluyen aquellos datos que revelen el origen racial o étnico, las opiniones políticas, las convicciones religiosas o filosóficas, la pertenencia a sindicatos así como datos relativos a la salud o a la sexualidad (artículo 8.1 de la Directiva). El tratamiento de estos datos estará prohibido salvo que concurra alguna circunstancia de las enumeradas en el artículo 8.2 de la Directiva de las que podemos considerar aplicables al periodismo: el consentimiento explícito del sujeto (subapartado a) o que el tratamiento se refiera a datos que el interesado haya hecho manifiestamente públicos (su- 
bapartado e). También se condiciona el tratamiento de los datos relativos a infracciones, condenas penales o medidas de seguridad que solo podrá realizarse bajo el control de la autoridad pública (artículo 8.5 de la Directiva).

Y, cuarta, condiciones de control sobre el tratamiento de los datos, básicamente, la obligación de notificación a la autoridad de control y las restricciones a la transferencia de datos a terceros países que no proporcionen un nivel de protección adecuado (artículos 18 y 25 de la Directiva, respectivamente) ${ }^{18}$.

Es fácilmente comprensible que el cumplimiento de estas obligaciones puede entrañar importantes restricciones al ejercicio de las libertades de expresión e información de los medios. Baste pensar en las implicaciones que la prohibición de tratamiento y difusión de datos sensibles supondrían para los medios que, entre otros pero muy mayoritariamente, cubren asuntos relacionados con información criminal o con opiniones políticas, por ejemplo. O las consecuencias que la obligación de informar a los interesados generaría para el periodismo de investigación o para las fuentes de información de los periodistas. Tampoco parece posible facilitar el derecho de acceso a y la rectificación de los datos personales durante la elaboración y redacción de la noticia y previamente a su publicación puesto que esto podría limitar gravemente la libertad de expresión. Finalmente, puede pensarse en lo inapropiada que resulta la prohibición de transferencia de datos a terceros países que no aseguren un nivel de protección adecuado para las actuales publicaciones electrónicas y versiones digitales de los medios de comunicación — periódicos, canales de televisión, emisoras de radio- y para los comunicadores online que gozan de difusión global.

\section{Análisis comparativo de la excepción periodística en la Unión Europea}

De los veintiocho países miembros de la Unión Europea, tan solo tres -Croacia, España y República Checa- ${ }^{19}$ no contemplan la excepción periodística en sus respectivas leyes de protección de datos lo que implica que la actividad periodística se encuentra sometida a todos sus preceptos. No obstante, debemos recordar el juicio de ponderación al que debe someterse obligatoriamente el ejercicio de ambos derechos lo que puede dar como resultado la prevalencia de las libertades de expresión y de información frente al derecho a la privacidad y que,

18 Seguimos el exhaustivo análisis que el profesor Erdos ha elaborado sobre el régimen europeo en materia de protección de datos y la legislación en materia de libertad de expresión e información, prensa y medios de comunicación de los 33 países que conforman el espacio económico europeo (ERDos, D., «Fundamentally Off Balance: European Union Data Protection Law and Media Expression», University of Cambridge. Faculty of Law Research Paper, n. ${ }^{\circ}$ 42/2014. Disponible en http://dx.doi.org/10.2139/ssrn.2471531).

19 Croacia: Personal Data Protection Act 103/03. España: Ley Orgánica 15/1999, de 13 de diciembre, de Protección de Datos de Carácter Personal (LOPD). República Checa: Act 101/2000 of April 4, on the Protection of Personal Data and on Amendment to Some Acts. Todas las leyes se citan en las versiones consultadas. 
en la práctica, no se apliquen a los medios algunas previsiones contempladas en la legislación sobre protección de datos.

En el resto de países de la UE es evidente la falta de sintonía en esta mate$\mathrm{ria}^{20}$. Las legislaciones nacionales de los Estados miembros van desde el reconocimiento de la primacía general de la libertad de expresión mediante amplias excepciones a los medios limitándose a imponerles el cumplimiento de las medidas de seguridad de los ficheros y las normas sobre responsabilidad como ocurre en Dinamarca, Finlandia o Suecia hasta aquellos sistemas que someten a la información periodística a restricciones previas con el objetivo de salvaguardar el derecho de habeas data de los particulares como es la situación actual en Hungría, Eslovenia o Eslovaquia pasando por países que aprovechan códigos deontológicos para encontrar un equilibrio entre las exigencias de protección de datos y la libertad de expresión e información como es el caso de Alemania, Italia o Reino Unido. Alemania los emplea para contrarrestar algunas excepciones muy amplias mientras que los códigos de prensa en Italia y Reino Unido puntualizan las generosas exenciones de su normativa sobre protección de datos en un sentido más restrictivo.

La observancia del principio de calidad de los datos se exige ampliamente a los medios de comunicación en las legislaciones nacionales. Salvo Alemania, Dinamarca, Finlandia y Suecia ${ }^{21}$ que eximen de su cumplimiento, el resto de países imponen a los medios estas condiciones para la licitud del tratamiento de los datos personales (Bélgica, Bulgaria, Chipre, Eslovaquia, Eslovenia, Estonia, Francia, Grecia, Hungría, Letonia, Luxemburgo, Países Bajos, Portugal y Rumania $)^{22}$. Los demás Estados miembros matizan sus previsiones. Por un lado, la existencia de interés público en la información excluye la aplicación de estos

20 Para un seguimiento de las legislaciones nacionales, resulta de interés el informe anual que aprueba el GT 29 con las novedades de cada Estado miembro en materia de protección de datos. Todos los informes pueden consultarse en http://ec.europa.eu/justice/data-protection/article-29/documentation/annual-report/ index_en.htm.

21 Alemania: Federal Data Protection Act (BDGS), 14 January 2003. Dinamarca: Act No. 429 of 31 May 2000, on Processing of Personal Data. Finlandia: Personal Data Act (523/1999) of 22 April 1999 y Suecia: Personal Data Act (1998:204), 29 April.

22 Bélgica: Act of 8 December 1992 on the Protection of Privacy in relation to the Processing of Personal Data. Bulgaria: Law for Protection of Personal Data 1/4, 4 January 2002. Chipre: Law 138(I)2001, 23 November, on the processing of Personal Data (Protection of Individuals). Eslovaquia: Act 122/2013, 30 April, on the Protection of Personal Data. Eslovenia: Personal Data Protection Act 15 July 2004. Estonia: Personal Data Protection Act of 15 February 2007. Francia: Loi n. $.^{\circ} 78-17$ du 6 janvier 1978, relative à l'informatique, aux fichiers et aux libertés. Grecia: Law 2472/1997, 10 April, on the Protection of Individuals with regard to the Processing of Personal Data. Hungria: Act CXII of 2011 on the Right of Informational Self-Determination and on Freedom of Information. Letonia: Personal Data Protection Law, of 23 March 2000. Luxemburgo: Loi du 2 août 2002 relative à la protection des personnes à l'égard du traitement des données à caractère personnel. Países Bajos: Act of 6 July 2000 containing Rules for the Protection of Personal Data. Portugal: Lei n. ${ }^{\circ}$ 67/98, de 26 de Outubro, da Protecção de Dados Pessoais. Rumania: Law No. 677/2001, of 21 November 2001, on the Protection of Individuals with Regard to the Processing of Personal Data and the Free Movement of Such Data. 
principios a los medios en Austria, Irlanda, Malta, Polonia y, destacadamente, Reino Unido ${ }^{23}$. En este último país, la Data Protection Act tampoco aplica los principios de calidad si el procesamiento de datos se realiza con vistas a la publicación de material periodístico, literario o artístico y, en un precepto técnicamente complejo, exige que el responsable del tratamiento crea, razonablemente, que la publicación es de interés público y que el cumplimiento de la normativa sobre protección de datos resulta incompatible con los fines del periodismo ${ }^{24}$. En la práctica, la norma británica pone el énfasis en el autocontrol de los medios respondiendo a la tradición inglesa de autorregulación de la prensa. Tampoco Italia aplica estos principios a los medios pero el Código deontológico para el Tratamiento de Datos en el Periodismo ${ }^{25}$ obliga al periodista a rectificar los errores y datos inexactos y a mantenerlos durante el periodo necesario para alcanzar las finalidades propias de su profesión (artículos 4 y 2.4 del Código, respectivamente).

Las reglas de transparencia no han de observarse por los medios en el caso de Alemania, Austria, Chipre, Dinamarca, Finlandia, Lituania, Países Bajos, Portugal y Suecia. Contrariamente, Eslovaquia y Eslovenia obligan siempre a informar a los interesados de la recogida y tratamiento de sus datos. El resto de legislaciones nacionales introducen matices y eximen de informar al interesado cuando el coste es excesivamente alto (Hungría), cuando su aplicación pudiera revelar la fuente de información (Bélgica, Luxemburgo y Rumanía), si existe un interés público preponderante (Bulgaria, Estonia, Francia, Letonia, Malta, Polonia y Reino Unido), siempre que la recogida de información se refiera a personajes públicos (Grecia) o si los datos han sido revelados directamente por los interesados o por medio de su comportamiento en público (Italia).

En lo que respecta al derecho de acceso, Bulgaria, Chipre, Estonia, Grecia, Hungría, Letonia, Eslovaquia lo imponen a los medios mientras que Austria, Finlandia, Letonia, Países Bajos y Suecia eximen siempre. Existe un grupo de países que dispensan de cumplir con la obligación de informar del tratamiento al interesado cuando existe interés público en la información (Estonia, Francia, Irlanda, Malta, Polonia y Reino Unido), para proteger a las fuentes (Italia y Rumanía), al propio periodista (Alemania) o si lo aprueba la autoridad de control (Luxemburgo y Portugal). En el caso de Dinamarca todavía cabe la negativa del medio a permitir ese acceso cuando ello implique excesivas dificultades para obtener la información.

23 Austria: Federal Act concerning the Protection of Personal Data (DSG 2000), 1 January 2000. Irlanda: Data Protection Acts 1988 and 2003 (Informal consolidation). Malta: Data Protection Act XXVI of 14 December 2001. Polonia: Act of 29 August 1997, on the Protection of Personal Data, n. ${ }^{\circ} 133$. Reino Unido: Data Protection Act 1998 (1998 Chapter 29), 16 July.

24 Artículo 32.a) de la Ley de Protección de Datos británica. Sobre la excepción periodística en Reino Unido puede consultarse Pauner Chulvi, C., «Privacidad y periodismo: el escándalo Murdoch sobre escuchas telefónicas en News of the World», Revista de Derecho Político, n. ${ }^{\circ} 88,2013$, pp. 245-288.

25 Codice di deontologia relativo al trattamento dei dati personali nell'esercizio dell'attività Giornalistica, Provvedimento del Garante del 29 luglio 1998, Gazzetta Ufficiale 3 agosto 1998, n. ${ }^{\circ} 179$. 
La posibilidad de aplicar la excepción periodística al tratamiento de categorías especiales de datos es, sin duda, la que menor reflejo ha tenido en las legislaciones nacionales. Tan solo Alemania, Austria, Finlandia y Suecia contemplan este privilegio para los medios de comunicación. En el caso de Italia, aunque el Código en materia de Protección de Datos exime a los periodistas de la prohibición de tratamiento de datos especialmente protegidos, el Código deontológico para el Tratamiento de Datos en el Periodismo incluye numerosas previsiones y cautelas para la publicación de informaciones sobre datos de salud y sexuales de personas identificadas e identificables obligando a «respetar la dignidad, el derecho a la intimidad y al decoro personal». No obstante, admite la publicación de ambos tipos de datos referidos a personas que revisten una posición de particular relevancia social o pública atendiendo al criterio del interés público de la información (artículos 10 y 11 del Código deontológico). El resto de Estados miembros mantienen la prohibición con matices. Acumulativamente, los países exigen el consentimiento por escrito del interesado (Hungría y Eslovaquia), la autorización previa de la autoridad de control (Lituania) o la comprobación de que existe ese consentimiento (Portugal). Cuando media interés público en la noticia se autoriza el tratamiento de datos sensibles en las normativas de Chipre, Estonia, Francia, Irlanda, Letonia, Malta, Polonia y Reino Unido. Asimismo, estas categorías especiales de datos pueden ser sometidas a tratamiento por los medios si se han hecho públicos por el propio interesado, se trata de un personaje público, la información está relacionada con su faceta pública o por la naturaleza pública del suceso en el caso de Bélgica, Bulgaria, Grecia, Luxemburgo y Rumanía.

Finalmente, es frecuente que las normativas nacionales enerven la aplicación de las condiciones de control sobre el tratamiento de los datos con fines periodísticos. Comenzando por la obligación de notificación a la autoridad de control, esta se impone en cualquier caso a los medios de comunicación en Chipre, Eslovaquia, Grecia, Portugal, Rumanía y Reino Unido así como en Estonia (cuando se trata de alguna categoría especial de datos), Letonia (cuando se trata de datos relativos a la salud o a delitos o se van a transferir a terceros países) y Dinamarca (obliga a notificar los ficheros electrónicos internos de los medios de comunicación excepto en el caso de que incluyan, únicamente y sin ninguna alteración, datos que ya han sido publicados por los medios). Se exime siempre de notificar en Alemania, Austria, Bélgica, Eslovenia, Finlandia, Hungría, Irlanda, Italia, Lituania, Luxemburgo, Países Bajos y Suecia mientras que Bulgaria, Malta y Polonia dispensan de esta obligación si media interés público en la información y Francia no somete a los medios al deber de notificar a condición de contar con un delegado en materia de protección de datos. Las restricciones a la transferencia de datos a terceros países que no proporcionen un nivel de protección adecuado no se aplican nunca en Alemania, Austria, Bélgica, Dinamarca, Eslovenia, Finlandia, Italia, Lituania, Países Bajos y Suecia. Tampoco lo hacen en Bulgaria, Estonia, Malta, Polonia, Francia y Luxemburgo cuando existe interés público. En Rumanía, las condiciones o requisitos para transferir datos personales a un tercer Estado no se aplicarán 
en el caso de que se traten con fines exclusivos de periodismo si los datos han sido hechos públicos por el sujeto afectado, están relacionados con su faceta pública o por el carácter público de la actividad en la que esté involucrado. Chipre, Eslovaquia, Grecia, Hungría, Irlanda, Letonia y Portugal son los países cuya legislación en materia de protección de datos prohíbe a los medios de comunicación transferir los datos sin excepciones.

En España, la LOPD no contempla ninguna excepción para la profesión periodística o para cualquier otra actividad relacionada con el manejo de información si atendemos al ámbito de aplicación de la norma (artículo 2.2 LOPD) ni se incluye esta actividad entre las que se rigen por sus disposiciones específicas (artículo 2.3 LOPD). Sin embargo, el artículo 3.j LOPD se refiere a los medios de comunicación como «fuentes accesibles al público» y considera legítimo un tratamiento de datos personales en ausencia del consentimiento del interesado si, entre otros, «los datos figuran en fuentes accesibles al público» según dispone el artículo 6.2 LOPD y dicho tratamiento «no vulnera los derechos y libertades fundamentales del interesado» lo que obliga a realizar una ponderación de los intereses en juego. En este ejercicio de equilibrio, la libertad de expresión y el derecho a la información, reconocidos como derechos fundamentales en el artículo 20.1 CE, disfrutan de prioridad en su relación con el derecho a la protección de datos bajo determinadas condiciones. Los parámetros generales que la jurisprudencia española y la AEPD emplean para realizar la ponderación a la que se refiere el artículo 6.1 LOPD son: primero, determinar si se hallan en juego las libertades informativas, por un lado, y el derecho a la protección de datos, por otro; segundo, resolver si lo comunicado es relevante en el sentido de que tiene «interés público» lo que dará prevalencia a las libertades informativas; tercero, lo publicado no debe desvelar innecesariamente datos personales o datos que no resulten significativos para la información. Por su parte, la inexistencia de la denominada excepción periodística no ha constituido ningún obstáculo para que la jurisprudencia la considere implícitamente reconocida en nuestro ordenamiento jurídico ${ }^{26}$ debiendo entenderse como manifestación del principio de proporcionalidad al que se refiere el artículo 4.1 LOPD $^{27}$.

26 La Audiencia Nacional, en sentencia de 12 de enero de 2001, afirma «que en la legislación española no existe un tratamiento específico de la concurrencia del tratamiento de datos automatizados de datos personales con la libertad de información, en contra de lo que ocurre en la normativa europea. En esta línea, la Sala quiere indicar que el Convenio para la protección de las personas con respecto al tratamiento de datos automatizados de datos de carácter personal (BOE de 15 de noviembre de 1985), establece en su art. 9.2 b) como excepción a las garantías de los arts. 5, 6 y 8 "la protección de los derechos y libertades de otras personas", expresión que la doctrina no duda en referir a la libertad de información de hecho en el preámbulo se dice que el art. 9.2 b) se refiere entre otros a los intereses de terceros, tales como, por ejemplo, "la libertad de prensa"».

27 La AEPD estima que «pese a la carencia de regulación específica en España en lo referido al tratamiento de datos personales con fines exclusivamente periodísticos o de expresión artística o literaria, como dispone el artículo 9 de la Directiva, la mejor doctrina entiende que visto el contenido del art. 6.1 de la LORTAD (LOPD), a cuyo tenor «el tratamiento de los datos de carácter personal requerirá el consentimiento inequívoco del afecta- 
Este repaso por la regulación de las excepciones periodísticas en las legislaciones nacionales muestra claramente que en algunos Estados miembros no se garantiza un equilibrio eficaz entre la protección de datos y la libertad de expresión e información en los medios de comunicación y que la existencia de divergencias entre las normativas nacionales pueden conducir a distorsiones en el marco regulador de las actividades transfronterizas que los medios de comunicación desarrollan en la actualidad, especialmente en el mundo online ${ }^{28}$.

\section{LA LIBERTAD DE EXPRESIÓN E INFORMACIÓN EN LA PROPUESTA DE REGLAMENTO EUROPEO DE PROTECCIÓN DE DATOS}

En estos momentos nos encontramos inmersos en un proceso de reforma global de la normativa europea reguladora del derecho a la protección de datos de carácter personal puesto que la imparable evolución tecnológica y el nuevo entorno digital plantean importantes retos para la privacidad frente a los que las normas existentes no proporcionan ni el grado de armonización ni la eficacia necesarios.

Por este motivo, a comienzos de 2012, la Comisión Europea impulsó una modificación muy profunda de la legislación en esta materia ${ }^{29}$. El nuevo «paquete» está compuesto por un Reglamento propiamente dicho, en sustitución de la Directiva 95/46/CE, que establecerá un marco general para la protección de datos procesados en la Unión Europea ${ }^{30}$ y una Directiva de mínimos que sustituirá a la Decisión marco 2008/977/JHA y establecerá normas sobre protección de datos personales tratados para los fines de la prevención, detección, investigación y enjuiciamiento de los delitos y las actividades judiciales ${ }^{31}$.

do, salvo que la ley disponga otra cosa»; la expresión «salvo que la ley disponga otra cosa», permite entender que no es necesario el consentimiento del afectado cuando el art. 20 de la CE permite el tratamiento. Lo que exigirá una ponderación del caso concreto, y desde los principios de adecuación, pertinencia y congruencia recogidos en el art. 4 de la LORTAD (LOPD) (...)» (Informe 624/2009 de la AEPD).

28 Comisión Europea, High Level Group on Media Freedom and Pluralism, A Free and Pluralistic Media to Sustain European Democracy, febrero de 2013. Disponible en https://ec.europa.eu/digital-agenda/sites/ digital-agenda/files/HLG\%20Final\%20Report.pdf.

29 Comisión Europea, Comunicación de la Comisión al Parlamento Europeo, al Consejo, al Comité Económico y Social y al Comité de las Regiones, La protección de la privacidad en un mundo conectado. Un marco europeo de protección de datos para el siglo XXI [COM (2012) 9 final, Bruselas, 25.1.2012]. Un excelente análisis del recorrido de la reforma en RALlo Lombarte, A., «Hacia un nuevo sistema de protección de datos: claves de la reforma», Revista de Derecho Político, n. ${ }^{\circ} 84,2012$, pp. 13 a 56, especialmente, pp. 21 a 34.

30 Comisión Europea, Propuesta de Reglamento del Parlamento Europeo y del Consejo relativo a la protección de las personas físicas en lo que respecta al tratamiento de datos personales y a la libre circulación de esos datos (Reglamento General de Protección de Datos) COM (2012) 11 final, Bruselas, 25.1.2012.

31 Comisión Europea, Propuesta de Directiva relativa a la protección de las personas físicas en lo que respecta al tratamiento de datos personales por las autoridades competentes para fines de prevención, investigación, detección o persecución y enjuiciamiento de los delitos y el libre movimiento esos datos [COM (2012) 10 final, Bruselas, 25.1.2012]. 
Tras la aprobación de los sucesivos borradores de la Propuesta de Reglamento Europeo de Protección de Datos por la Comisión en enero de 2012, el Parlamento en marzo de 2014 y el Consejo en junio de 2015 se ha dado paso a la fase final de negociación a tres bandas con el propósito común de alcanzar un acuerdo definitivo a finales de 2015.

La excepción periodística también aparece regulada en la Propuesta de Reglamento en dos de sus enunciados: en el Considerando 121 del Preámbulo y en el artículo $80^{32}$. En ambos preceptos se incluye una mención a la CDFUE uno de cuyos mandatos es la búsqueda del equilibrio con el objeto de conciliar el derecho a la protección de datos con las normas que rigen la libertad de expresión. Efectivamente, su artículo 52.1 determina que cualquier limitación del ejercicio de los derechos y libertades reconocidos por ella podrá responder «a la necesidad de protección de los derechos y libertades de los demás». A lo que debe añadirse que la nueva regulación europea sobre protección de datos ofrece suficiente cobertura para eximir de la aplicación de sus previsiones con el objeto de alcanzar «la protección del interesado o de los derechos y libertades de otras personas» [artículo $21.1 \mathrm{f}$ ) de la Propuesta de Reglamento].

La Propuesta de Reglamento mantiene que las prescripciones exentas de aplicarse a las actividades periodísticas son las relativas a los principios generales, los derechos del interesado, el responsable y encargado del tratamiento, la transferencia de datos a terceros países u organizaciones internacionales, las autoridades de control independientes, la cooperación y la coherencia, y situaciones específicas de tratamiento de datos y prohíbe a los Estados miembros establecer exenciones de las demás disposiciones del Reglamento (Considerando 121).

En el nuevo texto merece destacarse como innovación más remarcable la desaparición de la fórmula «fines exclusivos periodísticos o de expresión artística o literaria» puesto que se interpretó que no era suficientemente amplia y podría causar problemas a las empresas de comunicación que manejan datos personales necesarios para el desarrollo de su trabajo aunque su tratamiento no sea específicamente periodístico. Asimismo, se entiende que la supresión clarifica que la exención y protección se refieren al ejercicio de la libertad de expresión en general y no solo al realizado por periodistas, artistas o escritores.

En lugar de estas expresiones, la Propuesta de Reglamento remite al artículo 11 CDFUE que reconoce la libertad de expresión, opinión y la libertad de recibir o de comunicar informaciones o ideas, incluye la pauta de que, en atención a la importancia del derecho a la libertad de expresión en toda sociedad democrática, los conceptos relativos a la libertad de expresión deben ser interpretados en sentido amplio y desarrolla un intencionadamente generoso significado de esta expre-

32 Un estudio genérico sobre la consideración de los medios de comunicación en la Propuesta de Reglamento puede verse en PAuner Chulvi, C., «Implicaciones del futuro Reglamento Europeo sobre Protección de Datos en la libertad de información», en Los derechos a la intimidad y a la privacidad, A. Fayos (ed.), Dykinson, 2015, pp. 181-198. 
sión calificando como tales a aquellas actividades cuyo objeto es «la comunicación al público de información, opiniones o ideas, con independencia del medio que se emplee para difundirlas, teniendo asimismo en cuenta el desarrollo tecnológico».

Se trata, sin duda, de una novedad fundamental porque amplia el ámbito de aplicación de la exención periodística a modalidades de difusión de la información que anteriormente no se beneficiaban automáticamente de la prerrogativa. Explícitamente, la Propuesta de Reglamento descarta que tenga que tratarse de «empresas de comunicación» lo que unido a la aceptación de la comunicación online, pone el acento no tanto en el sujeto - particulares o medios de comunicación- como en la finalidad de los tratamientos. Esto es, la excepción periodística no se consagra como privilegio de los medios de comunicación —empresas de prensa, radiodifusión o televisión o periodistas - sino que resulta también aplicable a los tratamientos de datos realizados por ciudadanos siempre que se lleven a cabo en ejercicio del periodismo.

Finalmente, la Propuesta de Reglamento incluye también una importante excepción en favor de la libertad de información que afecta al conocido periodísticamente como derecho al olvido 33 —ahora, bajo la denominación de derecho a la supresión- regulado en su artículo 17. Este derecho permite a los ciudadanos solicitar del responsable del tratamiento la supresión de los datos que le conciernen y que se abstenga de darles más difusión y, en relación con terceros, a que estos supriman todos los enlaces a los datos personales, copias o reproducciones de los mismos cuando los datos ya no son necesarios en relación con los fines para los que fueron recogidos o tratados; cuando el interesado retira el consentimiento en que se basa el tratamiento, se opone al mismo o cuando ha expirado el plazo de conservación autorizado y no existe otro fundamento jurídico para el tratamiento de los datos.

El derecho al olvido, no obstante, tampoco goza de un carácter absoluto y hay casos en los que existen razones legítimas para mantener los datos en una base de datos (los archivos de un periódico son un buen ejemplo) ${ }^{34}$. Por ello, el Consi-

33 La bibliografía sobre el derecho al olvido es muy extensa por lo que nos limitaremos a señalar la obra clásica de Mayer-Schönberger, V., Delete. The virtue of forgetting in the digital age, Princenton University Press, Princeton, 2009 y, en nuestro país, las recientes monografías de Rallo Lombarte, A., El derecho al olvido en Internet. Google vs España, CEPC, Madrid, 2014 y SimON CASTELlano, P., El régimen constitucional del derecho al olvido, Tirant lo Blanch, Valencia, 2012. Sobre la incidencia del derecho al olvido en los medios, puede consultarse CASINO RuBIO, M., «El periódico de ayer, el derecho al olvido en internet y otras noticias», Revista Española de Derecho Administrativo, n. ${ }^{\circ}$ 156, 2012, pp. 201-216 y ZÁrAte Rojas, S., «La problemática entre el derecho al olvido y la libertad de prensa», Derecom, n. ${ }^{\circ} 13,2013$. Disponible http://dialnet.unirioja. es/servlet/articulo? codigo $=4330379$.

34 Así lo reconoce la STJUE de 13 de mayo de 2014, caso Google vs AEPD, en la que el Tribunal expone los límites del derecho al olvido y reconoce que el editor de una página web que publica información relativa a una persona física y lo hace «con fines exclusivamente periodísticos» puede beneficiarse, en virtud del artículo 9 de la Directiva, de las excepciones a los requisitos que ésta establece, beneficio que no cabe hacer extensivo al gestor de un motor de búsqueda puesto que no lo considera parte de los medios de comunicación y no disfruta, por tanto, de los derechos de la prensa o del derecho a informar (parágrafo 85). Un comentario sobre el pronunciamiento en Rallo Lombarte, A., «'Right to be forgotten' ruling is an Internet privacy 
derando 53 de la Propuesta de Reglamento prevé que la invocación de este derecho quedará limitada y deberá autorizarse la posterior conservación de los datos «cuando sea necesario para fines de investigación bistórica, estadística y científica, por razones de interés público en el ámbito de la salud pública, para el ejercicio del derecho a la libertad de expresión...». O, en dicción del artículo 17.3 de la Propuesta, se procederá a la supresión de los datos por el responsable del tratamiento «salvo en la medida en que la conservación de los datos personales sea necesaria: (a) para el ejercicio del derecho a la libertad de expresión de conformidad con lo dispuesto en el artículo 80».

\section{CONCLUSIONES}

Transcurridos veinte años desde la aprobación de la Directiva europea sobre protección de datos, la elaboración de un nuevo marco europeo regulador de la materia se antoja una necesidad imperiosa para adaptar esas normas a un escenario y unas condiciones muy distintas a aquellas bajo las que surgió la anterior normativa. Actualmente, los riesgos que Internet plantea para la protección de datos personales - recogidos e intercambiados en una escala sin precedentesno pueden ser afrontados sin un régimen armonizado que garantice que el derecho fundamental a la protección de datos de carácter personal se aplica de forma integradora y coherente en todas las políticas de la Unión Europea y en todos sus Estados miembros.

Uno de los ejemplos de la fragmentación que actualmente presentan las normativas nacionales en materia de protección de datos lo constituye la aplicación de la denominada excepción periodística, reconocida en el artículo 9 de la Directiva, que permite descartar la aplicación de algunas reglas y principios sobre protección de datos para garantizar el ejercicio legítimo del derecho a la libertad de expresión e información. La heterogeneidad de las regulaciones estatales abarca un amplio abanico de situaciones que, en sus extremos, van desde un porcentaje cercano al veinte por ciento de Estados miembros que no contemplan la mencionada excepción en sus leyes sobre protección de datos lo que, en la práctica, supone el incumplimiento de la normativa por parte de los medios de comunicación a otro porcentaje similar de países que establecen una exención casi total para los medios a pesar de los graves efectos que la difusión indiscriminada e ilegítima de información puede tener sobre los interesados.

Este panorama se verá modificado con la aprobación del nuevo Reglamento Europeo de Protección de Datos que, en lo que a la excepción periodística se refiere, introduce novedades muy importantes puesto que reformula su alcance en términos más amplios y claros.

watershed», Privacy Laws $\mathcal{E}$ Business, issue 129, June 2014, pp. 1-4. Disponible en http://www.privacylaws. com/Documents/PLB_INT_SPL/intnews129.pdf. 
En primer lugar, resolverá dos de las cuestiones más problemáticas que aquejan hoy en día al régimen de protección de datos en Europa, a saber, la inexistencia de una regulación global y uniforme de aquel derecho en todos los Estados miembros y la eficaz protección de los derechos fundamentales en el marco europeo. En relación con lo primero ha de destacarse el carácter de norma directamente aplicable del Reglamento acabando con el riesgo de fragmentación derivado del acto de transposición de las Directivas. Con relación a lo segundo, la Propuesta de Reglamento remite a los artículos de la CDFUE que reconocen el respeto de la vida privada y la protección de los datos de carácter personal como derechos fundamentales estrechamente relacionados pero independientes (artículos 7 y 8). Pero también incluye la mención del derecho de recibir o de comunicar informaciones, garantizado en el artículo 11, y reconoce explícitamente su importancia en la sociedad democrática lo que habrá de utilizarse como criterio para limitar la aplicación de algunas reglas sobre protección de datos en la búsqueda del equilibrio entre privacidad e información. Ambas cuestiones plantean un reto que no es sencillo de resolver. Porque, por un lado, no tiene sentido que en un régimen democrático los Estados puedan restringir o prohibir el free flow of news que favorece el debate público y una opinión pública más informada imponiendo reglas muy exigentes e inapropiadas como pudiera ser la obligación de recabar el consentimiento del interesado cuando se desee difundir datos especialmente protegidos en el contexto de una información sobre asuntos de interés público (Hungría, Eslovenia, Eslovaquia, entre otros). Pero, por otro lado, tampoco cabe excluir con carácter general a los medios de comunicación de la aplicación de la normativa en materia de protección de datos (Dinamarca, Finlandia o Suecia, entre otros) sin garantizar que la recogida, almacenamiento y difusión de los datos personales se lleva a cabo conforme a parámetros de legitimidad y sin vulneración de otros derechos personales.

En segundo lugar y como innovación destacable, el nuevo Reglamento suprime la restricción de que la prerrogativa sea aplicada «exclusivamente» a actividades periodísticas. No solo resultaba complejo dar con una definición exacta de lo que debía entenderse por periodismo sino que la exclusividad impedía que pudiesen beneficiarse de la excepción las actividades en las que concurría algún otro propósito además del de informar (comerciales, profesionales, políticos, entre otros). Además, la comunicación masiva a través de las redes sociales, utilizadas tanto por particulares como por empresas de comunicación y el surgimiento de nuevas formas de periodismo online plantean retos para los que la Directiva no contemplaba respuestas adecuadas.

El Considerando 121 de la Propuesta de Reglamento precisa con claridad que las excepciones a la aplicación de sus reglas pueden aplicarse a cualquier expresión pública de información, ideas y opiniones con independencia del medio que se emplee como canal de difusión y descarta que haya de tratarse en todo caso de organizaciones empresariales de comunicación. Las actividades de comunicación que se realicen online podrán, por tanto, beneficiarse de alguna excepción. 
Esto supondrá un reto para los Estados miembros a la hora de determinar el alcance de esa exención puesto que son muchos los peligros que la divulgación indiscriminada de información plantea para la privacidad de los internautas. Tal y como el propio Considerando señala, las exenciones y excepciones que los Estados miembros puedan adoptar a efectos de equilibrar los derechos fundamentales a la libertad de expresión y a la protección de datos deberán basarse, entre otros, en el responsable y el encargado del tratamiento. Esto significa que el tamaño o la estructura del responsable habrán de tenerse en cuenta a la hora de establecer el equilibrio entre los principios de la normativa sobre protección de datos y la libertad de expresión e información. Asimismo, se tendrá que discriminar entre aquellos contenidos de la blogosfera que tienen finalidad educativa, política, etc. y están enfocados a la formación de la opinión pública de aquellos — la mayoría- con un enfoque privado y el objetivo de mantener interacciones personales con amigos, comunidades, etc.

\section{$* * *$}

TITLE: Freedom of information as a restriction on the right to data protection: the journalism exemption

ABSTRACT: Indiscriminate application to the media of the rules on the right to data protection may cause excessive restriction of freedom of information, one of the most characteristic items of the legal heritage of democratic societies. In an attempt to strike a balance between the two fundamental rights, the European legal framework for the protection of personal data - the current Directive 95/46/EC and the proposed General Data Protection Regulation - provide for the so-called journalism exemption which allows Member States to establish exemptions to the application of certain provisions. This article analyses the concept and scope of this exemption in the European regulations and in the legislation of the Member States which have transposed the Directive into their national law and have thus incorporated recognition of the journalism exemption.

RESUMEN: La aplicación indiscriminada de la normativa sobre el derecho a la protección de datos de carácter personal a los medios de comunicación puede suponer una restricción excesiva de la libertad de información, uno de los elementos más característicos del patrimonio jurídico de las sociedades democráticas. En el intento de lograr un equilibrio entre ambos derechos fundamentales, el régimen europeo en materia de protección de datos - la actual Directiva 95/46/CE y la Propuesta de Reglamento General de Protección de Datoscontemplan la denominada excepción periodística que autoriza a los Estados miembros a establecer limitaciones a la aplicación de determinadas disposiciones. El presente artículo analiza el concepto y alcance de la mencionada excepción en las normas europeas y en las legislaciones de los Estados miembros que, en transposición de la Directiva, han incorporado el reconocimiento de la excepción periodística.

KEY WORDS: right to data protection, freedom of information, journalism exemption, mass media, Directive 95/46, General Data Protection Regulation.

PALABRAS CLAVE: derecho a la protección de datos personales, libertad de información, excepción periodística, medios de comunicación, Directiva 95/46, Reglamento General de Protección de Datos.

FECHA DE RECEPCIÓN: 07.01.2015

FeCHa de ACEPTACión: 29.07.2015 
